\title{
Grey prediction analysis of cutoff wall affected by construction effect
}

\author{
YUAN Hong-hu' ${ }^{1 a}$, Dai Yao ${ }^{2}$, Wang $\mathrm{Yu}^{2 *}$ \\ ${ }^{1}$.Beijing Institute of water, Beijing, 100048, China \\ 2. School of Mechanical Engineering, Xihua University
}

\begin{abstract}
The long-term stability analysis of cutoff wall affected by construction effect is crucial. The longterm stability of the cutoff wall of Daning Reservoir is mainly affected by the combined action of highway vehicle load, extreme highway load and water load under different water storage loads. In this paper, the prediction model and method of grey theory are used to predict the horizontal displacement at the top of the cutoff wall, the settlement at the top, the maximum principal stress of the reinforced concrete wall, and the maximum principal stress of the plastic concrete wall based on grey analysis with each storage and drainage cycle as the time series point combined with the actual situation of the project. The long-term stability of the cutoff wall under load is predicted and evaluated. The results show that the maximum stress of the monitoring $2-2$ section cutoff wall gradually tend to be stable during the whole storage and drainage cycle. The limit maximum compressive stress of reinforced concrete wall is $4.320 \mathrm{MPa}$, and the limit maximum compressive stress of plastic concrete wall is $1.758 \mathrm{MPa}$. Judging from the material strength, the maximum principal stress is within the design strength of the material, and the plastic failure of the wall does not occur, indicating that the combined anti-seepage system of rigid cutoff wall and plastic cutoff wall adopted by the Daning Reservoir is stable and safe in the later normal operation period.
\end{abstract}

\section{Introduction}

Some sections of the cutoff wall of Daning Reservoir are located in a large regional terrain difference. The upper wall is built first and then buried. There is a large amount of backfill soil on both sides of some walls. At the same time, a highway is planned to be built above the backfill area. The engineering disturbance is serious, and the safety of the cutoff wall needs to be monitored and evaluated during the construction period. After backfill construction, the main load form on both sides of the cutoff wall is the vehicle load of Jingshi highway. After the reservoir impoundment, it is necessary to consider the influence of water pressure on the cutoff wall and the surrounding soil to predict and evaluate the long-term stability of the cutoff wall.

Grey theory method is widely used in deformation prediction because it only needs a small number of data samples to effectively predict deformation. Zhang Jin, et $\mathrm{a}^{\left[{ }^{[1]}\right.}$ proposed a tunnel deformation prediction model using improved genetic algorithm to optimize grey neural network. Weng Zhijian, et a ${ }^{[2]}$ Aiming at the shortcomings of the grey GM ( 1,1$)$ model in predicting the settlement data sequence with large random fluctuation, combined with the grey theory model and Markov chain theory, a new dimension GM ( 1,1$)$ settlement prediction model based on Markov correction is established. Zhao Zilong ${ }^{[3]}$ proposed a differential grey neural network-AR model based on wavelet decomposition. Tang Chao, et al ${ }^{[4]} \mathrm{In}$ view of the fact that the traditional GM $(1,1)$ model cannot consider the influence of the external environment change on the system change trend and the shortcomings of the $\mathrm{GM}(1, \mathrm{~N})$ multivariate model in the model structure, the OGM $(1, \mathrm{~N})$ model is introduced and the adaptive mutation particle swarm optimization algorithm is used to optimize the background value for the error of the background value. Zheng Xudong et $\mathrm{al}^{[5]}$ reasonably combined the model based on the principle of maximum entropy and established a hybrid prediction model based on the principle of maximum entropy. Qi Lan, et $\mathrm{a}^{[6]}$ introduced the idea of iterative weight and genetic variation to improve the FOA algorithm of Drosophila optimization to improve its search ability and speed. Zhang Yinghao, et al ${ }^{[7]}$ introduced iterative data grouping technology to further improve the accuracy of grey Markov model for deformation prediction. Wang Xinsheng, et a ${ }^{[8]}$ used conventional GM ( 1,1$)$ model, homogeneous exponential function grey model and nonhomogeneous exponential function grey model to predict and compare the deformation of surrounding rock of tunnel. Shen Zhehui, et al ${ }^{[9]}$ established a non-equidistance grey-Markov model to predict the internal deformation of the dam. Guo Haiqing, et al ${ }^{[10]}$ combined with time-shift wavelet denoising and grey theory, studied the monitoring data of Jinping I hydropower station slope displacement,

Corresponding author: Wang Yu, xhwangyu@yeah.net

a'E-mail: bjyuanhonghu_@126.com 
proposed time-shift wavelet coefficient correlation denoising and wavelet-MGM ( $1, \mathrm{n})$ prediction model. Wang Feng, et $\mathrm{al}^{[11]}$ used dynamic multivariate grey model to predict the deformation of dangerous rock.

\section{Engineering background}

The Daning Reservoir is located in the north of Daning Village, Fangshan District, Beijing. The total storage capacity of the reservoir is 46.11 million $\mathrm{m}^{3}$, and the highest water level is $58.5 \mathrm{~m}$. It is surrounded by a plastic concrete vertical cut-off wall with a thickness of $0.60 \mathrm{~m}$ and a total length of $7.84 \mathrm{~km}^{[12]}$. Among them, the impervious wall of dujiakan section of Xidi passes under the Beijing Shijiazhuang Expressway to be expanded. The impervious wall of this section is composed of reinforced concrete impervious wall above ground and plastic concrete impervious wall below ground. The subgrade of Beijing Shijiazhuang expressway is composed of gravel soil backfilled and rolled on both sides of reinforced concrete wall.

Due to the reconstruction project of Beijing Shijiazhuang Expressway, dujiakan toll station is extended to Daning reservoir area. The extension scope includes the built impervious wall of the reservoir, pile number $\mathrm{xd} 0+$ $697.2 \sim \mathrm{xd} 0+835.9$, with a length of $138.7 \mathrm{~m}$. The cross influences position of highway and cutoff wall is shown in Figure $1^{[12]}$.

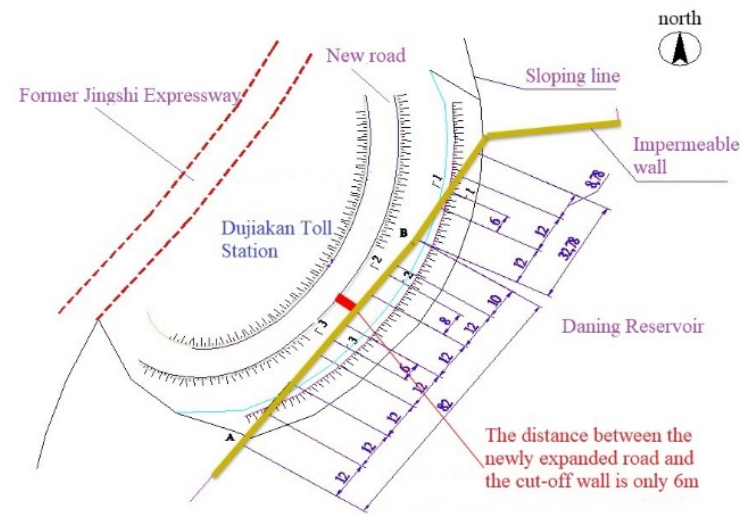

Figure 1. Schematic diagram of the Beijing-Shijiazhuang Expressway and the impervious wall of the reservoir

After the filling construction is completed, the construction near the cut-off wall is mainly the construction of the Dujiakan toll station on the BeijingShijiazhuang Expressway. The construction characteristics of this period are the small amount of construction earthwork and the long distance from the cutoff wall, which has very limited impact on the cut-off wall, so it is not considered in the long-term stability calculation; After the reconstruction project of Dujiakan toll station is completed and opened to traffic, the main load form on both sides of the cut-off wall is the vehicle load of Jingshi Expressway; After reservoir impoundment, the influence of water pressure on cutoff wall and surrounding soil should be considered at the same time.

According to the characteristics of the project, the long-term stability of the cut-off wall is mainly affected by road vehicle loads, different water storage loads, extreme road loads and water loads. This article mainly analyzes the stability of the cut-off wall under the above-mentioned load, and predicts the long-term stability. The analysis model is shown in Figure 2.

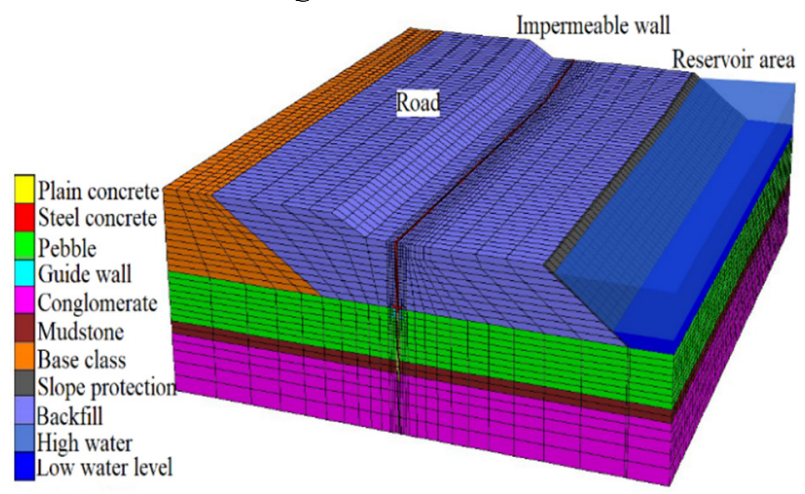

Figure 2. Long-term stability analysis model of cutoff wall

\section{GM $(1,1)$ gray model}

The $\operatorname{GM}(1,1)$ model establishes an approximate differential equation by performing gray transformation processing on univariate data, converts it into a matrix form, and solves the matrix to predict the value of the variable at the next moment. The prediction process is:

1) Select the initial data series with equal time intervals, This sequence is the data sequence to be predicted

$$
X^{(0)}=\left(x^{(0)}(1), x^{(0)}(2), \cdots, x^{(0)}(n)\right)
$$

Where $x^{(0)}(n)$ represents the time series data at time $\mathrm{n}$ 。

2) Perform an accumulation generation on the initial data sequence $X^{(0)}$ (1-AGO, AGO is the accumulation symbol), and generate a new sequence $X^{(1)}$ :

$$
X^{(1)}=\left(x^{(1)}(1), x^{(1)}(2), \cdots, x^{(1)}(k), \cdots, x^{(1)}(n)\right)
$$

$$
\begin{aligned}
\text { 其中 } & x^{(1)}(k) \text { 为: } \\
& x^{(1)}(k)=\sum_{i=0}^{k} x^{(0)}(i), \quad k=1,2, \cdots, n
\end{aligned}
$$

3) Establish the $\operatorname{GM}(1,1)$ prediction model, which is the first-order linear differential equation of $X^{(1)}$ :

$$
\frac{d X(t)^{(1)}}{d t}+a X(t)^{(1)}=u \quad t \in[0, \infty]
$$

4 ) Solve differential equations, use differential equations to make predictions

For a sequence of accumulated numbers, when $x^{(1)}(k)$ is known, the prediction function $x^{(1)}(k+1)$ of $x^{(1)}$ is:

$$
x^{\prime(1)}(k+1)=\left(x^{(0)}(1)-\frac{u}{a}\right) e^{-a k}+\frac{u}{a}
$$

Thus the predicted value of the original sequence $x^{(0)}$ is: 


$$
\left\{\begin{array}{l}
x^{\prime(0)}(1)=x^{(0)}(1) \\
x^{(0)}(k+1)=x^{\prime^{(1)}}(k+1)-x^{\prime(1)}(k)=\left(1-e^{a}\right)\left(x^{(0)}(1)-\frac{u}{a}\right) e^{-a k} \quad k=1,2, \cdots, n
\end{array}\right.
$$

Based on the above prediction model and method of grey theory, combined with the actual situation of the project, taking each storage and drainage cycle as the time series point, based on the grey analysis. The horizontal displacement of the top of the cutoff wall, the settlement of the top, the maximum principal stress of the reinforced concrete wall and the maximum principal stress of the plastic concrete wall are predicted respectively.

\section{Prediction of Deformation Law of Cutoff Wall}

\subsection{Predict sample parameters}

The main source of the predicted sample parameters is the model parameters in the process of multiple reservoir storage and drainage. There are 4 parameters to be predicted, and their values are shown in Table 1. From the calculated parameter table, it can be seen that in each storage and drainage cycle, the difference between the parameters of water storage and drainage is small, so in the gray analysis, each adjacent water storage and drainage process is regarded as a time series point. The value is the average of the two, and the final data sequence table for gray analysis is shown in Table 2.

Table1. Table of calculation results of parameters to be predicted

\begin{tabular}{|c|c|c|c|c|}
\hline $\begin{array}{c}\text { Time } \\
\text { schedule }\end{array}$ & $\begin{array}{l}\text { Horizontal } \\
\text { displacement } \\
\text { of wall top } \\
\quad(\mathrm{mm})\end{array}$ & $\begin{array}{c}\text { Wall } \\
\text { settlem } \\
\text { ent } \\
(\mathrm{mm} \\
)\end{array}$ & $\begin{array}{c}\text { Maximum } \\
\text { principal stress } \\
\text { of steel concrete } \\
(\mathrm{MPa})\end{array}$ & $\begin{array}{l}\text { The maximum } \\
\text { principal stress of } \\
\text { plain concrete } \\
(\mathrm{MPa})\end{array}$ \\
\hline $\begin{array}{l}\text { After the } \\
\text { construct } \\
\text { ion is } \\
\text { over }\end{array}$ & 17.57 & 5.043 & 1.069 & 0.876 \\
\hline $\begin{array}{l}\text { Water } \\
\text { storage } \\
\text { for the } \\
\text { first time }\end{array}$ & -42.52 & 4.666 & 2.793 & 1.435 \\
\hline $\begin{array}{l}\text { First } \\
\text { drain }\end{array}$ & -42.74 & 4.523 & 3.803 & 1.423 \\
\hline $\begin{array}{l}\text { Second } \\
\text { impound } \\
\text { ment }\end{array}$ & -61.86 & 4.896 & 5.36 & 1.704 \\
\hline $\begin{array}{l}\text { Second } \\
\text { drainage } \\
\text { Third }\end{array}$ & -62.23 & 4.553 & 5.987 & 1.463 \\
\hline $\begin{array}{l}\text { impound } \\
\text { ment }\end{array}$ & -63.3 & 4.591 & 6.116 & 1.535 \\
\hline $\begin{array}{c}\text { Third } \\
\text { drainage } \\
\text { Fourth }\end{array}$ & -61.81 & 4.725 & 5.023 & 1.46 \\
\hline $\begin{array}{l}\text { impound } \\
\text { ment }\end{array}$ & -63.93 & 4.724 & 5.049 & 1.532 \\
\hline $\begin{array}{l}\text { Fourth } \\
\text { drainage } \\
\text { Fifth }\end{array}$ & -64.14 & 4.849 & 5.032 & 1.542 \\
\hline $\begin{array}{l}\text { impound } \\
\text { ment }\end{array}$ & -65.7 & 4.751 & 5.161 & 1.565 \\
\hline $\begin{array}{c}\text { Fifth } \\
\text { drainage }\end{array}$ & -63.62 & 4.76 & 5.122 & 1.557 \\
\hline
\end{tabular}

Table2. Parameter table used in grey analysis

\begin{tabular}{ccccc}
\hline $\begin{array}{c}\text { Time } \\
\text { series }\end{array}$ & $\begin{array}{c}\text { Horizontal } \\
\text { displacement } \\
\text { of wall top } \\
(\mathrm{mm})\end{array}$ & $\begin{array}{c}\text { Wall } \\
\text { settlement } \\
(\mathrm{mm})\end{array}$ & $\begin{array}{c}\text { Maximum } \\
\text { principal } \\
\text { stress of steel } \\
\text { concrete } \\
(\mathrm{MPa})\end{array}$ & $\begin{array}{c}\text { The maximum } \\
\text { principal stress of } \\
\text { plain concrete } \\
(\mathrm{MPa})\end{array}$ \\
\hline 1 & -62.045 & 4.7245 & 5.6735 & 1.5835 \\
2 & -62.555 & 4.658 & 5.5695 & 1.4975 \\
3 & -64.035 & 4.7865 & 5.0405 & 1.537 \\
4 & -64.66 & 4.751 & 5.161 & 1.565 \\
\hline
\end{tabular}

According to the prediction results, the maximum stress of the impervious wall of the section 2-2 during the entire storage and drainage cycle gradually stabilized. The ultimate maximum compressive stress of the reinforced concrete wall is $4.320 \mathrm{MPa}$, and the ultimate maximum compressive stress of the plastic concrete wall is $1.758 \mathrm{MPa}$.

\section{5 conclusion}

The results show that from the point of view of material strength, the maximum principal stress is within the range of material design strength, and the wall has no plastic failure, indicating that Daning adopts a combined antiseepage system of rigid anti-seepage wall and plastic antiseepage wall. The reservoir is stable and safe in the later period of normal operation.

\section{Author}

Yuan Honghu, male, 1984-, $\mathrm{PhD}$, senior engineer, deputy director, mainly engaged in survey, design and scientific research in water conservancy engineering and geotechnical engineering.

\section{References}

1. Zhang Jin, Chen Lin, Lai Zulong. Improved genetic algorithm to optimize gray neural network tunnel deformation prediction[J]. Science of Surveying and Mapping, 2021, 46(02): 55-61+77.

2. Weng Zhijian, Qiu Chenjie, Qiu Fuxiang, Yang Yunhong, Lu Rufa, He Shenglong. Grey GM $(1,1)$ settlement prediction model based on Markov optimization and its application[J]. Science Technology and Engineering, 2020, 20(29): 12065 12070.

3. Zhao Zilong. Differential gray neural network-AR model based on wavelet decomposition and its application in subway tunnel settlement prediction[J]. Bulletin of Surveying and Mapping, 2020(S1): 99103.

4. Tang Chao, Chen Yanying, Li Shulin, Liu Yinchi, Hu Jingyun, Peng Fuhua. Improved OGM $(1, N)$ based on adaptive mutation particle swarm optimization algorithm and its application in dumping yard deformation prediction[J]. Chinese Journal of Rock Mechanics and Engineering, 2020, 39(S1): $3197-$ 3205 . 
5. Zheng Xudong, Chen Tianwei, Deng Jieli, Duan Qingda, Gan Ruo, Wang Lei. Application of entropy weight method parallel combination model in dam deformation monitoring $[\mathrm{J}]$. Hydropower, 2019, 45(03): 115-119.

6. Qi Lan, Li Qixian. Box culvert settlement prediction based on improved FOA-GM $(1,1)$ gray prediction model[J]. Hydropower Energy Science, 2018, 36(06): 129-132.

7. Zhang Yinghao, Liu Xiaoqing, Ning Xinyang. Application of gray-Markov model in dam deformation prediction of South Russia 5 Hydropower Station[J]. Water Resources and Hydropower Technology, 2018, 49(02): 139-143.

8. Wang Xinsheng, Zuo Weiqin, Zhou Chengtao, Chen Yu, Hou Yabin. Tunnel surrounding rock deformation prediction based on inhomogeneous exponential function gray model[J]. Modern Tunnelling Technology, 2017, 54(01): 105-109.

9. Shen Zhehui, Huang Teng, Tang Youhui. The application of gray-Markov model in dam internal deformation prediction[J]. Engineering of Surveying and Mapping, 2015, 24(02): 69-74.

10. Guo Haiqing, Zhang Min, Huang Tao, Ai Chunbin. Research on slope displacement prediction model based on time-lapse wavelet-gray theory[J]. Journal of Yangtze River Scientific Research Institute, 2015, 32(09): 146-152.

11. Wang Gaofeng, Sun Xiujuan, Sun Xiangdong, Gao Youlong, Wang Hongde, Le Qilang, Shi Xuelei. Application of dynamic multivariate grey model in the prediction of dangerous rock deformation $[\mathrm{J}]$. Journal of Hohai University (Natural Science Edition), 2014, 42(06): 508-512.

12. Beijing Institute of Water Resources Planning and Design. On-site monitoring and analysis of the impact of construction on the seepage wall of the west embankment of Daning Reservoir in Beijing [R]. Beijing: Beijing Institute of Water Resources Planning and Design, 2012. 